\title{
SÍNDROMES DE MUNCHAUSEN E MUNCHAUSEN POR PROCURAÇÃO: ALGUNS APONTAMENTOS DA PSICOLOGIA
}

\section{ARTIGO DE REVISÃo}

RIBEIRO, Thayanne Mayul de Souza Borges ${ }^{1}$

RIBEIRO, Thayanne Mayul de Souza Borges. Síndromes de Munchausen e Munchausen por Procuração: alguns apontamentos da Psicologia. Revista Científica Multidisciplinar Núcleo do Conhecimento. Ano 05, Ed. 05, Vol. 09, pp. 90 98. Maio de 2020. ISSN: 2448-0959, Link de acesso: https://www.nucleodoconhecimento.com.br/psicologia/sindromes-demunchausen

\section{RESUMO}

O artigo tem como intuito apresentar alguns apontamentos da psicologia acerca das síndromes de Munchausen (SM) e Munchausen por Procuração (SMPP), buscando compreender os termos e os sintomas. E, posteriormente, fornecer subsídios para os profissionais da área de saúde para uma possível intervenção e tratamento. A partir de uma revisão da literatura, por meio de consulta de dados eletrônicos e livros publicados disponíveis, priorizando os textos de 1999 até 2019 sobre o assunto. Observa-se que a literatura aponta a Síndrome de Munchausen como uma patologia mais comum do que se diagnostica acometendo indivíduos bem informados sobre a medicação a ser utilizada para o tratamento da doença que acreditam ter. Enquanto na Síndrome de Munchausen por Procuração as vítimas são crianças levadas geralmente ao serviço de saúde por suas mães ou responsável. Torna-se essencial o aprimoramento no atendimento, sobretudo quando a vítima é a criança.

${ }_{1}$ Psicóloga. Especialista em Saúde Mental e Atenção Psicossocial E em Terapia Cognitiva Comportamental Faculdade Brasileira de Ensino, Pesquisa e Extensão. Licenciatura em Pedagogia Faculdade FORTIUM-DF. 
Palavras-chave: Síndrome de Munchausen, sintomas, síndrome de Munchausen por procuração.

\section{INTRODUÇÃO}

O Barão de Muchausen foi um militar alemão que participou da guerra contra os turcos em meados do século XVIII, tornou-se uma figura conhecida por perambular pelas cidades, contando estórias fantasiosas de feitos impossíveis. O médico inglês Richard Ascher homenageou este personagem ao utilizar o termo Síndrome de Munchausen para designar uma desordem psiquiátrica.

Uma característica importante observada nesses pacientes com relação ao transtorno a relutância dos mesmos em realizar o tratamento psicológico após a alta hospitalar. Ao serem confrontados com esta possibilidade há uma intensificação dos sinais e sintomas apresentados. É difícil compreender as razões pelas quais estes indivíduos desenvolvem esse quadro, ainda mais quando a simulação dos sintomas ocorre com uma criança, e é produzido por sua própria mãe, justamente aquela quem deveria ser responsável pelo cuidado e proteção do filho. Acredita-se que a intenção é se beneficiar da atenção dispensada pela equipe de saúde para a suposta doença apresentada pela criança (PIRES e MOLLE, 1999).

A pesquisa foi norteada pela seguinte questão: como deve ser a postura adotada pelos profissionais diante de um caso de Síndrome de Munchausen, sobretudo quando a vitima é uma criança e a mãe ou responsável pelo cuidado dela é a pessoa que produz a doença, assumindo-a indiretamente por procuração.

O tema é relevante cientificamente, pois atualmente há poucos estudos relacionados ao assunto, raramente abordados nos currículos dos profissionais da área de saúde. Os profissionais encontram dificuldades em diagnosticar as síndromes, dentre outros fatores, pelo pouco conhecimento que se tem a respeito das mesmas, decorrente de escassa literatura existente acerca do tema. Além disto, muitos pacientes negam a existência de uma doença de ordem psiquiátrica, além da postura do perpetrador de negar qualquer tipo de acusação, nos casos da Síndrome de Munchausen por 
Procuração. Torna-se fundamental compreender os sinais e sintomas relacionados às síndromes, conhecendo as características dos envolvidos e os mecanismos utilizados na simulação, a fim de fornecer subsídios para os profissionais da área de saúde no reconhecimento dessas patologias para uma possível intervenção e tratamento mais adequado.

\section{CONCEITUAÇÃO E CARACTERIZAÇÃO DA SÍNDROME DE MUNCHAUSEN}

Conforme Oliveira (2018) a síndrome de Munchausen foi citada a primeira vez, em 1951, pelo médico inglês Richard Ascher que apresentou o termo inspirado no Barão de Münchhausen, Karl Friedrich Hieronymus, que viveu em Hanover, na Alemanha no século XVIII. Braga (2007) cita Penna (1992) ao enfatizar que a doença recebe o nome de Síndrome de Munchausen (SM), pois, tal qual o Barão, os pacientes perambulam de hospitais em hospitais, contando histórias factícias sobre as doenças, criando sintomas com o intuito de captar a atenção da equipe médica.

O médico inglês Ascher cunhou o termo Síndrome de Munchausen para caracterizar uma desordem psiquiátrica que faz com que o indivíduo crie de forma intencional histórias fantasiosas com relação à saúde (NETO et al., 2017). Atualmente para o diagnóstico e provável tratamento, considera-se que as queixas simuladas costumam afetar órgãos diferentes ou variam no curso da doença.

A Classificação Estatística Internacional de Doenças e Problemas Relacionados à Saúde (CID-10), encontra-se dentro do grupo Outros transtornos da personalidade e de comportamento adulto (F68 presente dentro dos transtornos fictícios). Caracterizado pela simulação e manipulação recorrente de sintomas, por vezes com automutilação. Com a finalidade de ocasionar sinais e sintomas que se assemelham a uma patologia. A motivação é intrínseca e visa assumir o papel de doente para receber tratamento médico. Associa-se frequentemente a grandes transtornos de personalidade e das relações. 
O Manual Diagnóstico e Estatístico de Transtornos Mentais (DSM-5) classifica como um distúrbio factício imposto a si próprio. Os critérios diagnósticos são: A. o sujeito simula sinais psicológicos e físicos, produzindo lesões ou doenças; distúrbio factício B. age como doente incapaz ou lesionado; C. assume comportamento fraudulento mesmo na ausência de compensações externas claras; D. esse comportamento não é clarificado pelo distúrbio, semelhante a um delírio ou outra condição psicótica Específico; Episódios recorrentes muitos eventos de simulação de doença e/ou indução de lesão (NETO et al., 2017).

Aranha et al. (2007) ressalta que o transtorno factídio é caracterizado pela produção de sintomas por parte do paciente de modo proposital, cujo objetivo é de assumir o papel de doente e, desta maneira, ganhar atenção da equipe médica. Os pacientes colocam-se em situações de alto risco, como infecções recorrentes de pele devido à contaminação por fezes, hipoglicemias não explicáveis e recorrentes em pacientes com acesso à insulina, febre de causas indeterminadas ou uso indevido de medicações prescritas.

Os autores citados acima apontam uma característica importante observada nesses pacientes com relação ao transtorno à relutância dos mesmos em realizar o tratamento psicológico isolado de alta hospitalar. Ao serem confrontados com esta possibilidade há uma intensificação dos sinais e sintomas apresentados, muitos apresentam traços fortemente manipuladores, de forma a controlar a situação, mesmo lidando com profissionais experientes e competentes. Quando não conseguem controlar a situação tentam fugir do serviço, e param de frequentar o hospital onde estavam sendo acompanhados em seguida, buscam outro (ARANHA et al., 2007).

Os pensamentos, os sentimentos ou os comportamentos excessivos que o sujeito apresenta são acompanhados de um número de sintomas somáticos, cujas características são: pensamentos exagerados e recorrentes acerca da gravidade dos sintomas; nível acentuado de ansiedade sobre a própria saúde ou sintomas; aumento do tempo e de energia voltados para os sintomas ou problemas de saúde (ARAÚJO e NETO, 2014). 


\section{CONCEITUAÇÃO E CARACTERIZAÇÃO DA SÍNDROME DE MUNCHAUSEN POR PROCURAÇÃO}

Gueller (2009) menciona que em, 1977 Meadow denominou Síndrome de Munchausen por procuração (SMPP) como uma condição em que os pais ou responsáveis criam ou simulam sintomas de doenças nas crianças. Isso resulta em inúmeras intervenções e procedimentos médicos perigosos. O perpetrador aparentemente demonstra interesse e um envolvimento exacerbados no cuidado com a criança. Não obstante, é o responsável por produzir a doença assumindo-a indiretamente por procuração.

Conforme o DSM-5 o diagnóstico da Síndrome de Munchausen por Procuração é um distúrbio factício é visto como aquele imposto ao outro. O diagnóstico relaciona-se ao agressor e não vítima, uma vez que esta recebe um diagnóstico de abuso (DSMV, 2014). No entanto, a determinação atribuída a esta entidade e os critérios diagnóstico geram controvérsia no meio científico. As características assumidas pelo perpetrador ao assumir a doença indiretamente por procuração são de exacerbar os sintomas, falsificar ou produzir histórias clínicas, evidências laboratoriais, lesões físicas, além de induzir a hospitalizações com procedimentos terapêuticos arriscados (PIRES e MOLLE, 1999).

\section{DIAGNÓSTICO E MANEJO DAS SÍNDROMES}

O diagnóstico é realizado a partir de uma anamnese e exame físico cauteloso. Dados trazidos pelos familiares e de outros relatos médicos tornam-se essenciais. $\mathrm{O}$ diagnóstico diferencial relevante é a presença de uma doença física verdadeira. (GATTAZ et al., 2003). Muitos negam a existência de uma doença de ordem psiquiátrica. Quando a simulação é descoberta e a hipótese de uma doença física é descartada a sensação de cuidado desprendido inicialmente pela equipe do hospital passa a ser substituída por uma sensação de fracasso e rejeição associados frequentemente com sentimentos de raiva, frustração. 
Aranha et al. (2007) reafirmam que os sentimentos tendem, a despertar uma transferência negativa na equipe de saúde quando evidenciado a natureza factícia da doença. Há dificuldade em caracterizar o que motiva esses pacientes a agir desse modo. Acredita-se que estejam em busca de algo como aceitação e afeto. Estes sentimentos podem ter sido originados na relação estabelecida com os progenitores, e de alguma maneira é transferida aos profissionais de saúde. A abordagem recomendada é a de não confrontar o paciente, oferecendo-lhe medidas que possibilitem sua recuperação. E envolvendo-o no plano de tratamento (GATTAZ, 2003).

A estratégia fundamental no manejo desses pacientes é o diagnóstico precoce, segundo Aranha et al. (2007), a fim de prevenir desse modo um aumento do sofrimento e do risco de autolesões e exames desnecessários. Em estágios precoces da doença uma intervenção psiquiátrica tende a ser bem sucedida, além de uma psicoterapia auxiliar no reforço da identidade e autoestima.

É fundamental estabelecer com paciente um vínculo terapêutico. Powell e Boast (1993) citados por Gattaz et al. (2003) apontaram a Terapia Cognitiva comportamental como uma das abordagens para manejar essa síndrome. Propondo o treino de habilidades sociais e a psicoeducação. O objetivo do primeiro é de propiciar um repertório diversificado de comportamento social funcional para que o sujeito possa emitir comportamentos mais assertivos nas relações interpessoais expressando melhor os sentimentos, as opiniões sempre respeitando as alheias. O segundo busca motivar o indivíduo para o tratamento por meio da clarificação dos sintomas e do modelo cognitivo, compartilhando a conceituação cognitiva.

Entretanto não há um consenso quanto a melhor abordagem terapêutica a ser adotada para o tratamento da síndrome de Munchausen (ARANHA et al., 2007)., O uso de medicação antidepressiva, neurolépticos e ansiolíticos reduzem a ansiedade, e tem demonstrado resultados satisfatórios quando utilizados (GATTAZ et al., 2003).

A Síndrome de Munchausen por Procuração é uma patologia considerada como uma grave forma de violência infantil, já que a criança apresenta falsos quadros 
patológicos, produzidos por um dos seus responsáveis, normalmente a mãe. Sendo necessário que o profissional entre em contato com o Comitê de Proteção à Criança, o serviço social, a mãe e a criança são encaminhadas para a Vara da Infância (BORGES, 2016).

Braga (2007) menciona a técnica tripartide ao citar Bleichmar (1992), a mãe e a criança podem ser atendidas simultaneamente, uma vez que a relação entre ambas encontra-se abalada, esse tipo de psicoterapia, poderia possibilitar o resgate do vínculo entre a mãe e o filho, perdidas em meio à dor e o sofrimento. Pois, a mãe apresenta uma dificuldade emocional e precisa ser acolhida pela equipe, em um trabalho multidisciplinar. Para que ela possa encontrar suporte e aceitar o tratamento da sua patologia.

\section{CONSIDERAÇÕES FINAIS}

Verifica-se que há poucos estudos e publicações tanto sobre a Síndrome de Munchausen quanto a Síndrome de Munchausen por Procuração na língua portuguesa, isto termina dificultando o reconhecimento e adequado manejo da doença. A busca pelo esclarecimento faz da equipe de saúde verdadeiros investigadores, procurando informações em registro da saúde do paciente. Uma característica relevante observada nesses pacientes com relação ao transtorno ao serem confrontados com esta possibilidade há uma intensificação dos sinais e sintomas apresentados e quando não conseguem manipular a situação tentam fugir do serviço hospitalar. O reconhecimento da doença por parte da equipe de saúde é essencial para o tratamento. Embora o papel e a atuação dos profissionais de saúde, diante deste quadro ainda não estão bem definidos, principalmente do psicólogo devido à carência de informação e de publicação, acerca do diagnóstico e manejo da síndrome. E muitos pacientes negam a existência de uma doença de ordem psiquiátrica. $\mathrm{O}$ estudo em questão pode ser visto como base para que novas pesquisas possam ampliar a discussão e a compreensão acerca do tema. 


\section{REFERÊNCIAS}

ASSOCIAÇÃO AMERICANA DE PSIQUIATRIA. Manual Diagnóstico e estatístico de transtornos mentais DSM. 5 ed. Porto Alegre: Artmed, 2014.

ARANHA, G. et al. Transtorno Factídio: um desafio para as diversas especialidades. Revista Associação Médica Brasileira, n.86, v.1, p.14-19,2007. Disponível em: http://www.revistas.usp.br/revistadc/article/view/59168 Acesso em: 12 dez. 2019.

ÁRAUJO, C.; NETO, F.L. A nova classificação Americana para os Transtornos Mentais-o DSM-5. Revista Brasileira de Terapia Cognitiva Comportamental. v.16, n.1, p.67-82,2014.

Disponível em: http://pepsic.bvsalud.org/scielo.php?script=sci_arttext\&pid=S151755452014000100007 Acesso em: 12 jan. 2020.

BRAGA, M. S. Um Estudo teórico sobre a Síndrome de Munchausen por procuração. Trabalho de Conclusão (Especialização Psicologia Clínica-Ênfase na Infância). Instituto de Psicologia. Universidade Federal do Rio Grande do Sul. Porto Alegre, 21p. 2007.Disponível em: http://www.lume.ufrgs.br/bitstream/handle/10183/12293/000606736.pdf?sequence=1 Acesso em: 28 fev. 2020.

BORGES, Y. M. Reflexões Psicojurídicas sobre a Síndrome de Munchausen Por Procuração. Trabalho de conclusão de curso (graduação). Instituto Brasiliense de Direito Público-IDP. Escola de Direito de Brasília, 27p. 2016. Disponível em: http://dspace.idp.edu.br:8080/xmlui/handle/123456789/2082 Acesso em: 12 jan. 2020.

CID10. ORGANIZAÇÃO MUNDIAL DA SAÚDE. Classificação Estatística Internacional de Doenças e Problemas Relacionados à Saúde. São Paulo: Edusp, 2017. 
DSM-V-TR- Manual Diagnóstico e estatístico de transtornos mentais. Porto Alegre: Artmed, 2014.

GATTAZ, W. et al. Síndrome de Munchausen: Diagnóstico e Manejo Clínico. Revista de Associação Médica Brasileira. v. 49, n.2, p 220-224, 2003. Disponível em: https://www.scielo.br/scielo.php?pid=S0104-

42302003000200045\&script=sci_abstract\&tlng=pt Acesso mar.2020.

GUELLER, A. S. Falhas na operação transitivista materna na sindrome de Munchausen por procuração. Revista Latinoamericana de Psicopatologia Fundamental. v.12, n.2, p. 276-284, 2009. Disponível em: https://www.scielo.br/scielo.php?script=sci_arttext\&pid=S1415-47142009000200003 Acesso em 05 dez. 2019.

NETO, A.M. et al. Síndrome de Munchausen e síndrome de Munchausen por procuração:uma revisão narrativa. Syndrome and Munchausen syndrome by proxy: a narrative review. v.15, n.4, p. 516-521, 2017. Disponível em: https://www.scielo.br/scielo.php?pid=S167945082017000400516\&script=sci_arttext\&tlng=pt Acesso 19 jan.2020.

OLIVEIRA, D.R. Síndrome de Munchausen by Proxy: Características Psicopatólogicas e Personalidade dos Agressores. Tese (Dissertação de Mestrado Integrado em Medicina). Instituto de Ciências Biomédicas Abel Salazar. Universidade Federal do Porto, p.48.2018. Disponível em: https://repositorioaberto.up.pt/bitstream/10216/115436/2/283723.pdf Acesso em: 28 nov. 2019.

PIRES, J.M.; MOLLE, L. D.; Síndrome de Munchausen- relato de dois casos. Jornal de Pediatria, v.75, n.4, 281-286, 1999. Disponível em: http://www.jped.com.br/conteudo/99-75-04-281/port.pdf Acesso em: 07 fev. 2020.

Enviado: Maio, 2020.

Aprovado: Maio, 2020. 